\title{
Azathioprine pharmacokinetics after intravenous, oral, delayed release oral and rectal foam administration
}

E C Van Os, B J Zins, W J Sandborn, D C Mays, W J Tremaine, D W Mahoney, A R Zinsmeister, J J Lipsky

\begin{abstract}
Background-6-Mercaptopurine and its prodrug azathioprine are effective medications for refractory inflammatory bowel disease. However, use of these drugs has been limited by concerns about their toxicity. Colonic delivery of azathioprine may reduce its systemic bioavailability and limit toxicity.

Aim-To determine the bioavailability of 6-mercaptopurine after administration of azathioprine via three colonic delivery formulations.

Methods-Twenty four healthy human subjects each received $50 \mathrm{mg}$ of azathioprine by one of four delivery formulations (each $n=6$ ): oral; delayed release oral; hydrophobic rectal foam; and hydrophilic rectal foam. All subjects also received a $\mathbf{5 0}$ mg dose of intravenous azathioprine during a separate study period. Plasma concentrations of 6-mercaptopurine were determined by high pressure liquid chromatography.

Results-The bioavailabilities of 6-mercaptopurine after colonic azathioprine administration via delayed release oral, hydrophobic rectal foam, and hydrophilic rectal foam $(7 \%, 5 \%, 1 \%$; respectively) were significantly lower than the bioavailability of 6-mercaptopurine after oral azathioprine administration $(47 \%)$ by Wilcoxon rank sum pairwise comparison. Conclusions-Azathioprine delivered to the colon by delayed release oral and rectal foam formulations considerably reduced systemic 6-mercaptopurine bioavailability. The therapeutic potential of these colonic delivery methods, which can potentially limit toxicity by local delivery of high doses of azathioprine, should be investigated in patients with inflammatory bowel disease.

(Gut 1996; 39: 63-68)
\end{abstract}

Keywords: inflammatory bowel disease, Crohn's disease, ulcerative colitis, 6-mercaptopurine, azathioprine, pharmacokinetics.

Section of Biostatistics D W Mahoney

A R Zinsmeiste

Mayo Clinic, Mayo

Foundation,

Rochester, Minnesota

Correspondence to:

Dr W J Sandborn, Mayo

Clinic, 200 First Street SW,

Rochester, MN 55905, USA

Accepted for publication

19 January 1996
6-Mercaptopurine (6MP) and its prodrug azathioprine (AZA) have been used in the treatment of inflammatory bowel disease (IBD) for over 25 years. Multiple controlled trials and a recent meta analysis support the efficacy of 6MP and AZA in Crohn's disease. ${ }^{1-7}$ Controlled trials also support the use of AZA in ulcerative colitis, the most recent by Hawthorne and colleagues. ${ }^{8-12}$ However, use of $6 \mathrm{MP}$ and AZA for IBD has been limited by concerns about their toxicity, including dose related leucopenia, which is seen in $2-5 \%$ of patients treated in the long term with $6 \mathrm{MP}$ or AZA for IBD. ${ }^{13} 14$

Colonic drug delivery has the potential advantage of providing a local therapeutic effect with reduced systemic bioavailability, and thereby limited toxicity. This mode of delivery has been effectively used with both mesalamine and corticosteroids in patients with IBD. ${ }^{15}$ The aim of this study was to determine the bioavailability of 6MP after AZA delivery by three different colonic delivery methods. We studied AZA pharmacokinetics by determining 6MP bioavailability rather than AZA bioavailability because of the availability of reliable techniques for measuring plasma $6 \mathrm{MP}$ concentrations. In addition, $6 \mathrm{MP}$ is the more biologically relevant molecule, as AZA functions as a prodrug for $6 \mathrm{MP}$. After absorption, AZA is quickly converted to $6 \mathrm{MP}$ via non-enzymatic attack on the bond between the imidazole ring and the $6 \mathrm{MP}$ molecule by sulphydryl containing compounds such as glutathione. ${ }^{16} 6 \mathrm{MP}$ is further metabolised to the compounds with immunomodulatory activity, the 6-thioguanine nucleotides (6TGN). ${ }^{17}$ Demonstration of reduced $6 \mathrm{MP}$ bioavailability after colonic AZA delivery would provide the basis for a therapeutic clinical trial of this method of AZA administration in patients with IBD.

\section{Methods}

\section{Subjects}

Twenty four healthy human volunteers were recruited from January 1994 to August 1994 to participate in a study of AZA pharmacokinetics after four different delivery methods (oral, delayed release oral, hydrophobic rectal foam, hydrophilic rectal foam). The study protocol was approved by the Institutional Review Board of the Mayo Clinic and written informed consent was obtained prior to subject participation. Screening physical examination and laboratory studies (complete blood count, chemistry panel, and urine analysis) were performed. Prior to study entry, the erythrocyte thiopurine methyltransferase (TPMT) activity was determined in all subjects. This enzyme is critical for the catabolic metabolism of $6 \mathrm{MP}$. In the general population TPMT activity has a trimodal distribution: homozygous low TPMT 
activity ( $<5.0 \mathrm{U} / \mathrm{ml} \mathrm{RBC})$ occurs at a frequency of $0.3 \%$; heterozygous low TPMT activity (5.0-13.7 U/ml RBC) occurs at a frequency of $11.1 \%$; and normal TPMT activity (13.8-25.1 U/ml RBC) occurs at a frequency of $88 \cdot 6 \%$. ${ }^{18}$ Subjects with homozygous or heterozygous low TPMT activity were excluded from the study because of prior reports of severe neutropenia associated with AZA or $6 \mathrm{MP}$ use in this population. ${ }^{19}$ Subjects were screened for medical conditions or a surgical history that could affect AZA absorption or its metabolism. Table I summarises the demographics of the subject group.

Study design

The 24 healthy human subjects were randomly assigned to receive $50 \mathrm{mg}$ of AZA by one of four delivery formulations (each $n=6$ ): oral; delayed release oral (DRO); hydrophobic rectal foam (HBF); and hydrophilic rectal foam (HPF). All subjects also received a $50 \mathrm{mg}$ dose of intravenous AZA during a separate study period. The two doses of AZA were separated by at least three weeks and the order of dosing (intravenous $v$ non-intravenous) was randomly determined. Studies were performed in the General Clinical Research Center (GCRC) at the Mayo Clinic. Subjects fasted after midnight the night before the study. If a rectal foam was to be administered, the subject was given a Fleet enema if he/she had not had a bowel movement the morning of the study. The intravenous dose (see later) was administered as an infusion diluted in $20 \mathrm{ml}$ of normal saline and delivered over five minutes. The oral preparations were administered with a sip of water. Rectal formulations were administered by the GCRC nurse. Subjects remained fasting for three hours after dose administration. A time zero blood sample was obtained before the study. After dose administration or after initiation of the intravenous infusion, blood samples were drawn in $7 \mathrm{ml} \operatorname{EDTA}\left(\mathrm{K}_{3}\right)$-containing vacuum tubes (Sherwood Medical, St Louis, MO) at the following time intervals: 5 , $10,15,30$ minutes and $1,1 \cdot 5,2,3,4,5,6$, and 8 hours.

Determination of 6MP concentration in plasma Immediately after collection, blood samples were placed in an ice-water slurry. Within 30 minutes the blood sample was centrifuged for

TABLE I Subject group demographics

\begin{tabular}{|c|c|c|c|}
\hline $\begin{array}{l}\text { Group } \\
(n=6)\end{array}$ & $\begin{array}{l}\text { Age } \\
(y)\end{array}$ & $\begin{array}{l}\text { Weight } \\
(\mathrm{kg})\end{array}$ & $\begin{array}{l}T P M T \\
\text { (units/ml RBC) }\end{array}$ \\
\hline \multicolumn{4}{|l|}{ Oral } \\
\hline $\begin{array}{l}\text { Median } \\
\text { Range }\end{array}$ & $26 \cdot 8$ & $82 \cdot 2$ & $\begin{array}{l}20 \cdot 8 \\
10.5-25.5\end{array}$ \\
\hline \multicolumn{4}{|l|}{ DRO } \\
\hline Median & $28 \cdot 1$ & $72 \cdot 6$ & $20 \cdot 8$ \\
\hline $\begin{array}{l}\text { Range } \\
\mathrm{HBF}\end{array}$ & $23-62$ & $54 \cdot 6-172$ & $18 \cdot 4-24 \cdot 9$ \\
\hline \multicolumn{4}{|l|}{ HBF } \\
\hline $\begin{array}{l}\text { Median } \\
\text { Range }\end{array}$ & $28 \cdot 1$ & $81 \cdot 7$ & 21.9 \\
\hline $\begin{array}{l}\text { Range } \\
\text { HPF }\end{array}$ & $24-38$ & $72 \cdot 2-104$ & $20 \cdot 0-29 \cdot 3$ \\
\hline \multicolumn{4}{|l|}{ HPF } \\
\hline $\begin{array}{l}\text { Median } \\
\text { Range }\end{array}$ & 31 & $75 \cdot 2$ & $18 \cdot 9$ \\
\hline $\begin{array}{l}\text { Range } \\
\text { p Value }\end{array}$ & $26-46$ & $55 \cdot 3-80 \cdot 5$ & $17 \cdot 9-22 \cdot 9$ \\
\hline p Value & 0.6449 & 0.5176 & 0.0623 \\
\hline
\end{tabular}

10 minutes at $1000 \mathrm{~g}, 4^{\circ} \mathrm{C}$. Plasma was then transferred to plastic cryotubes (Nunc, Naperville, IL) and stored at $-70^{\circ} \mathrm{C}$ until analysis. $6 \mathrm{MP}$ concentrations were determined by high pressure liquid chromatography (HPLC) using the technique of $\mathrm{Zimm}^{20}$ with modifications. ${ }^{21}$ Solid phase extraction columns (C18 Sep-Paks, Waters, Millford, MA) were sequentially pre-rinsed with $2.5 \mathrm{ml}$ of methanol and $5 \mathrm{ml}$ of $0.2 \%$ acetic acid. One $\mathrm{ml}$ of plasma was loaded onto the Sep-Pak after addition of $0.04 \mathrm{ml}$ of saturated disodium EDTA (Aldrich, Milwaukee, WI) solution to the plasma. In addition, $0.1 \mathrm{ml}$ of standard solution was added to the plasma in the case of standard curve samples and $0.1 \mathrm{ml}$ of water for unknowns. The sulphydryl protecting agent dithiothreitol (DTT) was not included because AZA is immediately converted to $6 \mathrm{MP}$ in the presence of DTT. ${ }^{22}$ The cartridges were rinsed with $2 \mathrm{ml}$ of $0.2 \%$ acetic acid and then centrifuged at $2200 \mathrm{~g}$ for five minutes to remove excess water. The samples were eluted from the cartridges with $2 \mathrm{ml}$ of methanol and evaporated to dryness under a stream of nitrogen at $37^{\circ} \mathrm{C}$. Samples were then reconstituted in $200 \mu$ l of mobile phase, vortexed for 30 seconds, transferred to $1.5 \mathrm{ml}$ conical microfuge tubes, and centrifuged $11000 \mathrm{~g}$ in a microcentrifuge for five minutes. A portion $(0.175 \mathrm{ml})$ of supernatant was transferred to HPLC vials.

6MP concentrations were determined by HPLC. The analytical column was a HewlettPackard (Rockville, MD) octadecylsilane (ODS) Hypersil, $200 \times 4.6 \mathrm{~mm}, 5 \mu \mathrm{m}$ particle size. It was protected by a Zorbax (Mac-mod Analytical, Chadds Ford, PA) ODS $4 \times 12.5$ $\mathrm{mm}$ guard column and a $0.5 \mu \mathrm{m}$ particulate filter. The mobile phase was $0.8 \%$ acetonitrile in $1 \mathrm{mM}$ triethylamine, adjusted to $\mathrm{pH} 3 \cdot 2$ with phosphoric acid. Absorbance was monitored at $340 \mathrm{~nm}$. The injection volume was 80 $\mu l$. Unknowns were determined by comparing them with a standard curve constructed the same day by adding known quantities of $6 \mathrm{MP}$ to blank plasma. The lower limit of quantitation of $6 \mathrm{MP}$ was $2 \mathrm{ng} / \mathrm{ml}$. The mean calculated concentration (coefficient of variation) for the $2 \mathrm{ng} / \mathrm{ml}$ and $50 \mathrm{ng} / \mathrm{ml}$ standards were $2.0 \mathrm{ng} / \mathrm{ml}$ (18) $\%$ and $50.2 \mathrm{ng} / \mathrm{ml}(3.4) \%$, respectively.

\section{Study medications}

(1) Intravenous AZA, lyophilised as the sodium salt (Burroughs Wellcome, Research Triangle Park, NC). (2) Standard $50 \mathrm{mg}$ oral AZA capsule (Burroughs Wellcome, Research Triangle Park, NC). (3) Delayed release oral tablet. A $50 \mathrm{mg}$ oral AZA tablet (Burroughs Wellcome, Research Triangle Park, NC) is crushed and placed in a gelatin capsule. The capsule is then coated with Eudagit-S, a pH sensitive polymer that dissolves at $\mathrm{pH} 7.0$ in the terminal ileum or the colon. ${ }^{23}$ (4) Hydrophobic rectal foam. Administered rectally via a pressurised foam canister. Fifty mg of AZA (Fermion/Orion Corporation, Espoo, Finland) is dissolved in a foam containing witepsol $\mathrm{H} 15$ (an oleagenous base) to make it hydrophobic. (5) Hydrophilic rectal foam. 
Administered rectally via a pressurised foam canister. Fifty $\mathrm{mg}$ of AZA (Fermion/Orion Corporation, Espoo, Finland) is dissolved in a foam. The delayed release oral and rectal foam forms of AZA were prepared by Tillotts Pharma AG (Ziefen, Switzerland).

\section{Drug stability}

6MP and AZA concentrations are stable in whole blood when stored in an ice-water slurry for up to five hours. ${ }^{22} 6 \mathrm{MP}$ is stable in plasma when frozen for up to one year. ${ }^{22}$ The AZA formulations of delayed release oral, hydrophobic rectal foam, and hydrophilic rectal foam formulations were stable for up to one year as determined by HPLC in our laboratory. 6MP was stable for at least four hours in plasma at room temperature and for up to 30 hours in the extracted form at room temperature in our laboratory (data not shown).

\section{Parmacokinetic parameters}

Time to peak serum concentrations $\left(T_{\max }\right)$ was determined by inspection from the difference between the time of drug administration $\left(T_{0}\right)$ and the time of the highest measured concentration $\left(\mathrm{C}_{\max }\right)$. The area under the concentration versus time curve (AUC) was calculated as the sum of the area under the concentration curve from $T_{0}$ to $T_{z}$ determined by the linear trapezoidal rule, and the extrapolated area under the unmeasured tail of the curve $\left(A U C_{e x t}\right)$ using this equation: $\mathrm{AUC}_{\text {ext }}=\mathrm{C}_{\mathrm{z}}$ / beta. $T_{z}$ is the time of the last measurable concentration and $C_{z}$ is the last measured concentration. Beta, the terminal elimination rate constant, is the negative value of the slope of the terminal log-linear portion of the concentration versus time curve determined by least squares regression analysis. The serum clearance $\left(\mathrm{CL}_{\mathrm{b}}\right)$ is calculated using the following equation: $\mathrm{CL}_{\mathrm{b}}=\mathrm{D} / \mathrm{AUC} \mathrm{IV}_{\mathrm{IV}} \mathrm{D}$ is the dose given intravenously and $\mathrm{AUC}_{\mathrm{iv}}$ is the area under the concentration versus time curve after intravenous administration. Oral clearance and rectal clearance cannot be reliably calculated as the dose reaching the systemic circulation is variable. Bioavailability $(F)$ is calculated by the following equation: $\mathrm{F}=\mathrm{AUC}_{\mathrm{x}} / \mathrm{AUC}_{\mathrm{iv}}$. $\mathrm{AUC}_{\mathrm{x}}$ is the area under the concentration versus time curve after administration of AZA by one of the following routes: oral, DRO, HBF, HPF. The volume of distribution at steady state $\left(\mathrm{V}_{\mathrm{dss}}\right)$ was calculated utilising the mean residence time according to standard methods. ${ }^{24}$

\section{Statistical analysis}

The age, weight, and TPMT activity of the subject group; the AUC, $C L, V_{d s s}$, and $T_{1 / 2}$ for the intravenous studies; and the AUC, $F, T_{\max }$, and $\mathrm{C}_{\max }$, for the non-intravenous studies were compared using a non-parametric analysis of variance (Kruskal-Wallis test). Pairwise comparisons between groups were based on a Wilcoxon rank sum test.

\section{Results}

Twenty four subjects were enrolled and randomised to one of four possible non-intravenous administrations of AZA (oral, DRO, $\mathrm{HBF}$, and HPF). There were no statistically significant differences in age, body weight, and TPMT activity between the four groups (Table I).

The AUC, CL, $\mathrm{V}_{\mathrm{dss}}$, and $\mathrm{T}_{1 / 2}$ were used as indices for comparison of the intravenous studies among the four groups by the KruskalWallis test (Table II). There were no statistically significant differences among the groups, indicating that the baseline intravenous parameters of the groups were similar. For nonintravenous studies, the parameters AUC, F, and $\mathrm{C}_{\text {max }}$, were compared between groups by the Kruskal-Wallis test (Table III). $\mathrm{T}_{\max }$ was not observed in six of 24 subjects so no formal statistical test was conducted. The overall comparison among the four groups indicated significant differences for AUC, $F, C_{\text {max }}$ $(p=0.0014,0.0028$, and 0.0015 , respectively). Pairwise comparisons using the Wilcoxon rank sum test show AUC, F, and $C_{\max }$ for the oral formulation to be significantly higher than AUC, F, and $C_{\max }$ for the DRO, HBF, and HPF formulations. There were no significant

TABLE II Pharmacokinetic parameters for 6MP after 50 MG AZA administered intravenously

\begin{tabular}{|c|c|c|c|c|}
\hline $\begin{array}{l}\text { Group } \\
(n=6)\end{array}$ & $\begin{array}{l}A U C \\
(n g / h / m l)\end{array}$ & $\begin{array}{l}C L \\
(L / \mathrm{kg} / \mathrm{h})\end{array}$ & $\begin{array}{l}V d s s \\
(I / \mathrm{kg})\end{array}$ & $\begin{array}{l}T_{1 / 2} \\
(h)\end{array}$ \\
\hline \multicolumn{5}{|l|}{ Oral } \\
\hline Median & $116 \cdot 0$ & & $5 \cdot 56$ & $1 \cdot 1$ \\
\hline Range & $73 \cdot 0-135 \cdot 4$ & $2 \cdot 9-4 \cdot 6$ & $4 \cdot 1-7 \cdot 6$ & $1.0-1.5$ \\
\hline \multicolumn{5}{|l|}{ DRO } \\
\hline Median & 110.9 & $3 \cdot 3$ & $6 \cdot 3$ & $1 \cdot 1$ \\
\hline Range & $50 \cdot 9-162 \cdot 1$ & $2 \cdot 4-6 \cdot 7$ & $4 \cdot 0-11 \cdot 8$ & $1 \cdot 1-2 \cdot 6$ \\
\hline \multicolumn{5}{|l|}{$\mathrm{HBF}$} \\
\hline Median & $87 \cdot 9$ & $4 \cdot 1$ & $5 \cdot 5$ & $1 \cdot 2$ \\
\hline Range & $45 \cdot 6-119 \cdot 1$ & $2 \cdot 7-5 \cdot 8$ & $4 \cdot 3-15 \cdot 5$ & $0 \cdot 8-1 \cdot 6$ \\
\hline \multicolumn{5}{|l|}{ HPF } \\
\hline Median & $109 \cdot 6$ & $3 \cdot 5$ & $5 \cdot 7$ & $1 \cdot 0$ \\
\hline Range & $63 \cdot 1-134 \cdot 7$ & $3 \cdot 0-5 \cdot 7$ & $3 \cdot 9-9 \cdot 8$ & $0 \cdot 9-1 \cdot 4$ \\
\hline \multicolumn{5}{|l|}{ Overall } \\
\hline Median & $109 \cdot 6$ & $3 \cdot 3$ & $5 \cdot 6$ & $1 \cdot 1$ \\
\hline Range & $45 \cdot 6-162 \cdot 1$ & $2 \cdot 4-6 \cdot 7$ & $3 \cdot 9-15 \cdot 5$ & $0 \cdot 8-2 \cdot 6$ \\
\hline p Value & 0.6551 & 0.5229 & $0 \cdot 8638$ & 0.5044 \\
\hline
\end{tabular}

TABLE III Pharmacokinetic parameters for 6MP after 50 $M G A Z A$ administered via oral, $D R O, H B F$, and $H P F$

\begin{tabular}{|c|c|c|c|c|}
\hline $\begin{array}{l}\text { Group } \\
(n=6)\end{array}$ & $\begin{array}{l}A U C \\
(n g / h / m l)\end{array}$ & $\begin{array}{l}F \\
(\%)\end{array}$ & $\begin{array}{l}\text { Cmax } \\
(n g / m l)\end{array}$ & $\begin{array}{l}\text { Tmax } \\
\text { (h) }\end{array}$ \\
\hline \multicolumn{5}{|l|}{ Oral } \\
\hline Median & $41 \cdot 6$ & $47 \cdot 4$ & $16 \cdot 9$ & 2 \\
\hline Range & $32 \cdot 5-98 \cdot 8$ & $27-83$ & $8 \cdot 3-41 \cdot 8$ & $1-3$ \\
\hline \multicolumn{5}{|l|}{ DRO } \\
\hline Median & $9 \cdot 6$ & $7 \cdot 1$ & $3 \cdot 7 \|$ & $5 \|$ \\
\hline Range & $0-21 \cdot 8$ & $0-38 \cdot 7$ & $2 \cdot 5-12 \cdot 6$ & $5-6$ \\
\hline \multicolumn{5}{|l|}{ HBF } \\
\hline Median & 5.9 & $5 \cdot 3$ & 2.49 & 29 \\
\hline \multicolumn{3}{|l|}{ HPF } & $2 \cdot 2-2 \cdot 5$ & $1 \cdot 5-3$ \\
\hline Median & 1.8 & $1 \cdot 3$ & $2 \cdot 35^{a}$ & $2^{\mathrm{a}}$ \\
\hline Range & $0-9.6$ & $0-8.5$ & $2 \cdot 1-2 \cdot 7$ & $2-2$ \\
\hline p Value ${ }^{\star}$ & $0.0014 † \ddagger$ & $0.0028+5$ & $0.0015+5$ & \\
\hline
\end{tabular}

${ }^{\star} \mathrm{p}$ Values determined by Kruskal-Wallis test.

†Pairwise comparisons by Wilcoxan rank sum test: oral $>\mathrm{DRO}=\mathrm{HBF}=\mathrm{HPF}$.

$\ddagger$ Bonferroni adjustment of $p$ values for multiple pairwise comparisons (considered significant when $p$ value $\times 6$ was $<0.05$ ): oral $>\mathrm{DRO}=\mathrm{HBF}=\mathrm{HPF}$.

§Bonferroni adjustment of $p$ values for multiple pairwise comparisons (considered significant when $p$ value $\times 6$ was comparisons (considered significant when $\mathrm{p}$,
$<0.05$ ): oral $=\mathrm{DRO}$; oral $>\mathrm{HBF}$; oral $>\mathrm{HPF}$;

$<0 \cdot 05):$ oral $=$ DRO;
DRO $=\mathrm{HBF}=\mathrm{HPF}$.

$\mathrm{DRO}=\mathrm{HBF}=\mathrm{HPF}$.
$\|$ Median of five subjects with detectable concentrations of $6 \mathrm{MP}$. aMedian of four subjects with detectable concentrations of $6 \mathrm{MP}$. 


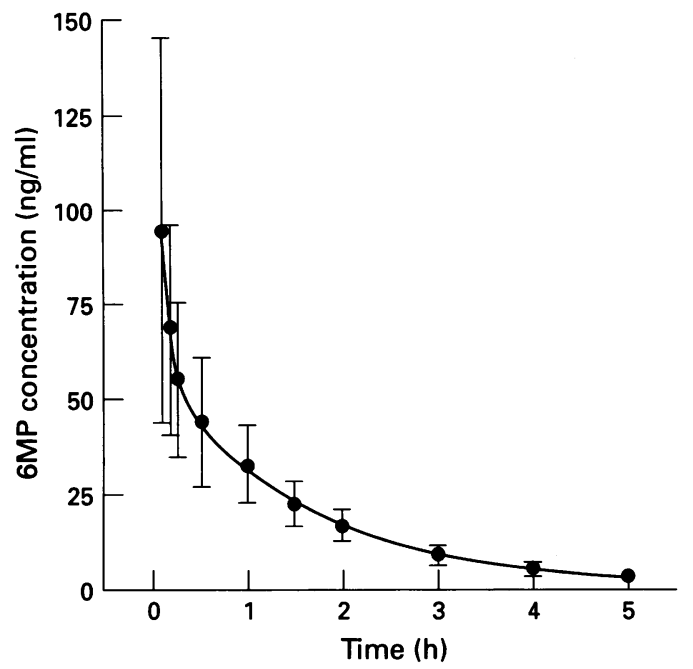

Figure 1: Model derived mean (SD) concentration versus time curve for 24 subjects after intravenous administration of $50 \mathrm{mg}$ of $A Z A$.

differences in AUC, $F$, and $\mathrm{C}_{\max }$ between the $\mathrm{DRO}, \mathrm{HBF}$, and $\mathrm{HPF}$ formulations. When $\mathrm{p}$ values were adjusted for six pairwise comparisons ( $p$ value $\times 6<0.05$ ), there were strong trends for the $\mathrm{F}$ and $\mathrm{C}_{\max }$ of the oral formulation to be significantly higher than the $F$ and $\mathrm{C}_{\max }$ of the DRO formulation. However, the adjusted $\mathrm{p}$ values did not reach significance at the $5 \%$ level $(p=0.0978$ and 0.0624 for $F$ and $\mathrm{C}_{\max }$, respectively). By inspection, the $\mathrm{T}_{\max }$ of the DRO formulation was greater than the $T_{\max }$ of the oral, HBP, and HPF formulations.

The blood concentration values after intravenous administration of AZA for each subject over time were fit to a two compartment model
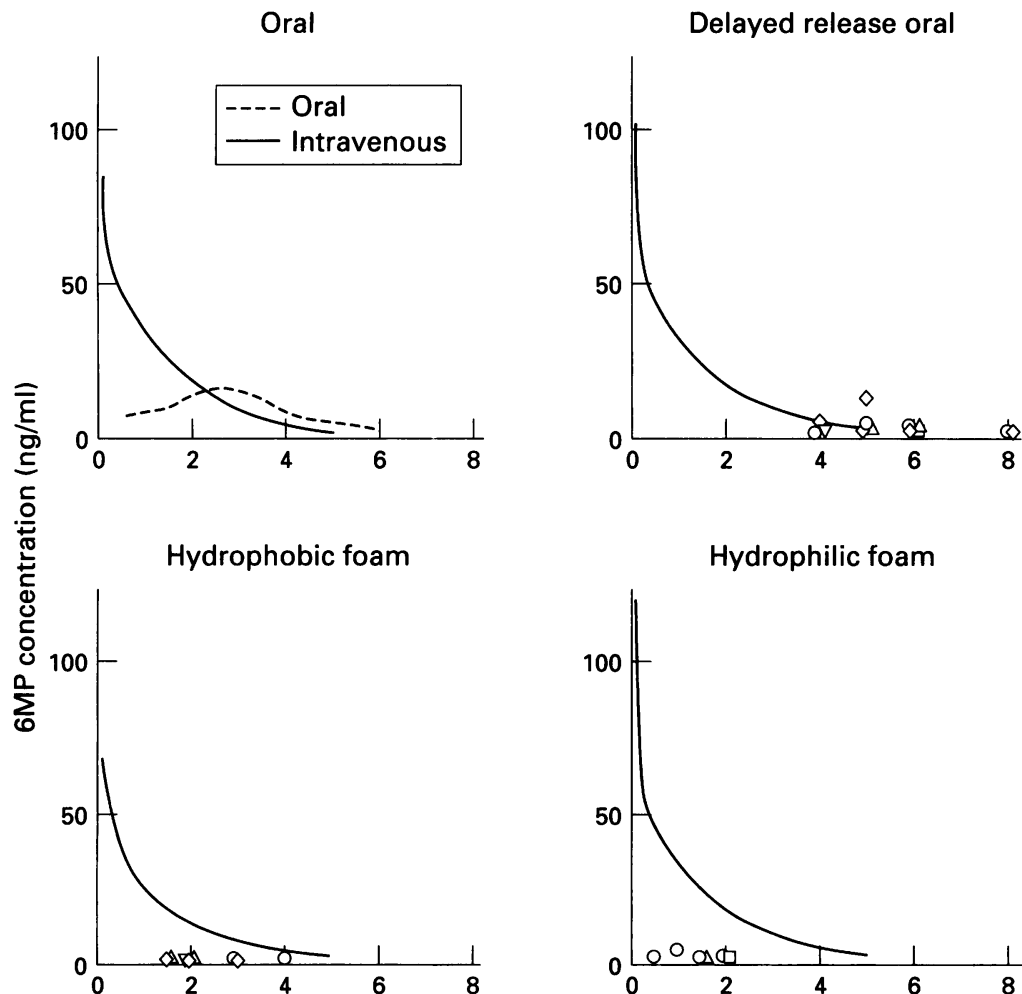

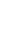

Time $(\mathrm{h})$

Figure 2: Model derived mean intravenous concentration versus time curves for each delivery group. For the oral group the mean observed concentration versus time curve is also plotted. For the DRO, HBF, and HPF groups the observed concentrations are plotted, with different symbols representing individual subjects. using PC NONLIN (Scientific Consulting, Apex, MC). Figure 1 depicts the mean (SD) of the model derived intravenous concentrations for all the intravenous studies at selected time points.

Figure 2 depicts the model derived mean intravenous concentration versus time curves for each of the delivery groups. Also plotted for the oral group is the mean observed concentration versus time curve. For the DRO, HBF, and HPF groups are plotted the observed concentrations, with different symbols representing individual subjects. We chose to present the data in this manner because there were not enough data points for the non-intravenous studies of the DRO, HBF, and HPF groups to create meaningful curves.

The rectal foam preparations were well tolerated. Ten of 12 subjects retained the foam for greater than six hours. One subject reported expelling the hydrophobic foam after one hour and another reported expelling the hydrophobic foam after two hours. The subject who reported expelling the foam after one hour did not have detectable absorption. The subject who reported expelling the foam after two hours had a $C_{\max }$ of $2.35 \mathrm{ng} / \mathrm{ml}$ at three hours. No adverse reactions to any of the drug preparations were reported.

\section{Discussion}

This study shows that there were significant differences in bioavailability of $6 \mathrm{MP}$ after dosing with oral, DRO, and rectal delivery formulations of AZA. When Wilcoxon rank sum pairwise comparison is performed between the groups, the bioavailabilities of $6 \mathrm{MP}$ after the DRO formulation and rectal delivery formulations were significantly less than after the standard oral AZA. After the conservative adjustment of $p$ values for multiple pairwise comparisons ( $p$ value $\times 6$ ), the $p$ value displayed a strong trend toward significance, limited only by the sample size. These data represent convincing evidence that the bioavailability of $6 \mathrm{MP}$ after AZA administration with the DRO and rectal formulations is significantly lower than after standard oral delivery.

To our knowledge, this is the first study reporting detailed pharmacokinetics of AZA after colonic administration in adult humans. Odlind and colleagues reported the only detailed previous study of $6 \mathrm{MP}$ and AZA pharmacokinetics after intravenous and oral AZA administration. ${ }^{25}$ They gave $100 \mathrm{mg}$ of intravenous AZA to 15 uraemic patients. The median (range) $\mathrm{CL}$ and $\mathrm{V}_{\mathrm{dss}}$ of $6 \mathrm{MP}$ after intravenous AZA were $6 \cdot 2 \mathrm{1} / \mathrm{kg} / \mathrm{h}(2 \cdot 0-18 \cdot 7)$ and $9.3 \mathrm{l} / \mathrm{kg}(2 \cdot 3-54 \cdot 2)$, respectively. This compares with our values of $3.3 \mathrm{1} / \mathrm{kg} / \mathrm{h}$ $(2 \cdot 4-6 \cdot 7)$ and $5.61 / \mathrm{kg}(3.9-15 \cdot 5)$ for CL and $\mathrm{V}_{\mathrm{dss}}$, respectively. Significant interindividual variation in these parameters has been previously reported. ${ }^{26}$ Odlind then gave a $100 \mathrm{mg}$ dose of oral AZA to eight uraemic patients. The median (range) $T_{\max }, C_{\max }$, and bioavailability of $6 \mathrm{MP}$ were $1.5(0.25-4 \cdot 0), 22.0 \mathrm{ng} / \mathrm{ml}$ $(7 \cdot 6-80 \cdot 7)$ and $41 \%(19-67)$, respectively. 
This compares with our values of $2.0(1-3)$, $16.9 \mathrm{ng} / \mathrm{ml}(8 \cdot 3-42)$, and $47 \%(27-83)$ after a $50 \mathrm{mg}$ oral dose. The results of the two studies suggest that the uraemic subjects may have a greater $\mathrm{CL}$ and $\mathrm{V}_{\mathrm{dss}}$ for $6 \mathrm{MP}$.

Colonic administration of corticosteroids and 5-aminosalicylate has been effectively utilised in patients with IBD. In the case of corticosteroids, reduced toxicity has been seen with colonic delivery. This decreased toxicity is due to reduced bioavailability. Several types of colonic drug delivery systems are currently available, including enemas ${ }^{15}$; rectal foams ${ }^{27}$; and delayed release oral formulations in the form of Eudragit coated capsules, which dissolve at $\mathrm{pH} 7$ in the terminal ileum. ${ }^{23}$

To date, information regarding colonic delivery of AZA and 6MP is limited to two pharmacokinetic studies of $6 \mathrm{MP}$ administered as a rectal suppository to rats ${ }^{28}$ and to children. ${ }^{29}$ In the rat study, a hydrophilic macrogol base suppository resulted in significantly higher bioavailability than a hydrophobic oleaginous base (witepsol H-15) suppository. In children given $6 \mathrm{MP}$ via standard oral and hydrophilic macrogol suppository routes, the hydrophilic base suppository had a mean AUC that was $4 \cdot 4$ times greater than the mean AUC for the oral dose. Rectal suppositories are delivered to a watershed region of the intestinal circulation where venous drainage is both portal and systemic. Direct systemic absorption of $6 \mathrm{MP}$ would probably result in increased bioavailability because first pass metabolism in the liver would be avoided. In contrast, our data show that when foam AZA preparations are delivered to the entire left colon (proximal to the rectum), 6MP bioavailability is negligible.

Our data show reduced 6MP bioavailability after colonic administration of AZA via a DRO capsule or rectal foam. There are several potential factors contributing to this finding. The most probable is that the absorption of AZA across the colonic mucosa is reduced compared with absorption across gastric and small intestinal mucosa. This may be due to absence of specific transport mechanisms or differing rates of passive absorption. AZA and $6 \mathrm{MP}$ may be more completely metabolised in the colonic mucosa than in the mucosa of the more proximal gastrointestinal tract. In addition, some AZA may be lost in the stool. Reduced colonic absorption compared with jejunal absorption has been demonstrated for 5-aminosalicylate. ${ }^{30}$ Faecal excretion of 5-aminosalicylate after administration of Eudragit coated tablets is approximately $25 \%$. $^{31}$ Though the effect of intestinal inflammation on the absorption of AZA has not been evaluated, a pharmacokinetic study of enteric coated 5-aminosalicylate demonstrated no difference between groups of subjects with small bowel Crohn's disease, total ulcerative colitis, and healthy volunteers. ${ }^{32}$

After absorption, AZA is quickly converted to $6 \mathrm{MP}$ in plasma. This conversion occurs as the result of non-enzymatic attack by sulphydryl containing compounds such as glutathione on the bond between the $6 \mathrm{MP}$ molecule and the imidazole ring of AZA. ${ }^{16}$ Glutathione is present in every mammalian cell, including colonic epithelial cells and lymphocytes. ${ }^{33}$ Previous studies have shown that lymphocytes contain the enzymes necessary to convert $6 \mathrm{MP}$ to the active metabolites, the $6 \mathrm{TGNs} .^{34}$ It is, therefore, reasonable to hypothesise that topical delivery of AZA will result in local immunosuppressive effects on colonic lymphocytes. In support of the hypothesis that local delivery of $6 \mathrm{MP}$ can be more efficacious compared with systemic delivery, use of parenteral $6 \mathrm{MP}$ infused into the renal artery resulted in prolonged survival and reduced toxicity compared with systemic intravenous $6 \mathrm{MP}$ in canine renal allograft recipients. ${ }^{35} 36$

Our study shows that colonic delivery of AZA results in significantly lower 6MP bioavailability than standard oral AZA. Colonic delivery of AZA could potentially reduce the drug's toxicity by reducing systemic exposure to $6 \mathrm{MP}$. In addition, this topical form of AZA administration may permit delivery of higher, locally concentrated doses to the colon. The therapeutic potential of colonic AZA delivery should be investigated in patients with IBD.

Supported by grants from the Mayo Foundation (WJS), Tillotts Pharma AG (WJS), USPHS FD-T-000-886 (JL), USPHS RR-00585.

Presented at the annual meeting of the American Gastroenterology Association, 15-17 May 1995, San Diego, CA, USA.

William J Sandborn, MD and the Mayo Foundation have applied for patents for delayed release oral and rectal foam azathioprine formulations.

1 Willoughby JMT, Kumar PJ, Beckett J, Dawson AM. Controlled trial of azathioprine in Crohn's disease. Lancet 1971; ii: 944-7.

2 Rosenberg JL, Levin B, Wall AJ, Kirsner JB. A controlled trial of azathioprine in Crohn's disease. Dig Dis 1975; 20: $721-6$

3 O'Donoghue DP, Dawson AM, Powell-Tuck J, Bown RL, Lennard-Jones JE. Double-blind withdrawal trial of azathioprine as maintenance treatment for Crohn's disease. Lancet 1978; ii: 955-7.

4 Present DH, Korelitz BI, Wisch N, Glass JL, Sachar DB, Pasternack BS. Treatment of Crohn's disease with 6-mercaptopurine, a long-term, randomized, double-blind captopurine, a long-term, randomized
study. $N$ Engl भ Med 1980; 302: 981-7.

5 Ewe K, Press AF, Singe CC, Stufler M, Ueberschaer B, Hommel G, et al. Azathioprine combined with prednisolone or monotherapy with prednisone in active nisolone or monotherapy with prednisone in active

6 Candy S, Wright JP, Gerber M, Adams G, Gerig M, Goodman R. A controlled double-blind study of azathioprine in the management of Crohn's disease. Gut 1995; 37: 674-8.

7 Pearson DC, May GR, Fick GH, Sutherland LR. Azathioprine and 6-mercaptopurine in Crohn's disease: a meta-analysis. Ann Intern Med 1995; 122: 132-42.

8 Jewell DP, Truelove SC. Azathioprine in ulcerative colitis: final report on a controlled therapeutic trial. $B M F$ 1974; 4: 627-39.

9 Caprilli R, Carratu R, Babbini M. A double-blind comparison of the effectiveness of azathioprine and sulfasalazine in
idiopathic proctocolitis. A preliminary report. Dig Dis 1975; 20: 115-20.

10 Rosenberg JL, Wall AJ, Levin B, Binder HJ, Kirsner JB. A controlled trial of azathioprine in the management of chronic ulcerative colitis. Gastroenterology 1975; 69: 96-9.

11 Kirk AP, Lennard-Jones JE. Controlled trial of azathioprine in chronic ulcerative colitis. $B M F$ 1982; 284: 1291-2.

12 Hawthorne AB, Logan RFA, Hawkey CJ, Foster PN, Axon ATR, Swarbrick ET, et al. Randomized controlled trial of azathioprine withdrawal in ulcerative colitis. $B M \mathcal{F} 1992$; 305: 20-2.

13 Present DH, Meltzer SJ, Krumholz MP, Wolke A, Korelitz BI. 6-Mercaptopurine in the management of inflammatory bowel disease: short- and long-term toxicity. Ann Intern Med 1989; 111: 641-9.

14 Connell WR, Kamm MA, Ritchie JK, Lennard-Jones JE. Bone marrow toxicity caused by azathioprine in inflammatory bowel disease: 27 years experience. Gut 1993; 34: matory bow.

15 Sutherland LR. Topical treatment of ulcerative colitis. Med Clin North Am 1990; 74: 119-31.

16 Chalmers AH. Studies on the mechanism of formation of 5-mercapto-1-methyl-4-nitroimidazole. A metabolite of the immunosuppressive drug azathioprine. Biochem Pharmacol 1974; 23: 1891-901. 
17 Lennard L. The clinical pharmacology of 6-mercaptopurine. Eur f Clin Pharmacol 1992; 43: 329-39.

18 Weinshilboum RM. Methylation pharmacogenetics: thiopurine methyltransferase as a model system. Xenobiotica 1992; 22: 1055-71.

19 Lennard L, Van Loon JA, Weinshilboum RM. Pharmacogenetics of acute azathioprine toxicity: relationship to thiopurine methyltransferase genetic polymorphism. Clin Pharmacol Ther 1989; 46: 149-54.

20 Zimm S, Ettinger LJ, Holcenberg JS, Kamen BA, Vietti TJ, Belasco J, et al. Phase 1 and clinical pharmacological study of mercaptopurine administered as a prolonged infusion. Cancer Res 1985; 45: 1869-73.

21 Van Os EC, McKinney JA, Zins BJ, Mays DC, Schriver Z, Sandborn WJ, et al. Simultaneous determination of azathioprine and 6-mercaptopurine by high performance liquid chromatography. Fournal of Chromatography B: Biomedical applications (in press).

22 Lilliemark J, Pettersson B, Lafolie P, Zweig T, Peterson C. Determination of plasma azathioprine and 6-mercaptopurine in patients with rheumatoid arthritis treated with oral azathioprine. Ther Drug Monit 1990; 12: 339-43.

23 Schroeder KW, Tremaine WJ, Ilstrup DM. Coated oral 5aminosalicylic acid therapy for mildly to moderately active ulcerative colitis. $N$ Engl F Med 1987; 317: 1625-9.

24 Rowland M, Tozer TN. Clinical pharmacokinetics. 2nd ed. Philadelphia, PA: Lea \& Febiger, 1989.

25 Odlind B, Hartvig P, Linström B, Lönnerholm GL, Tufveson G, Grefberg N. Serum azathioprine and 6-mercaptopurine levels in immunosuppressive activity after azathioprine levels in immunosuppressive activity after azathioprine

26 Zimm S, Collins JM, Riccardi R, O'Neill D, Narang PK, Chabner B, et al. Variable bioavailability of oral mercaptopurine. Is maintenance chemotherapy in acute lymphoblastic leukemia being optimally delivered? $N$ Engl $f$ Med 1983; 308: 1005-9.
27 Rectal topical corticosteroid preparations. Drug Ther Bull 1991; 29: 66-8.

28 Kato Y, Matsushita T, Yokoyama T, Mohri K. Enhanced bioavailability of 6-mercaptopurine after rectal administration in rats. Pharm Res 1992; 9: 697-9.

29 Kato Y, Matsushita T, Uchida H, Yokoyama T, Mohri K. Rectal bioavailability of 6-mercaptopurine in childre with acute lymphoblastic leukaemia: partial avoidance of 'first-pass' metabolism. Eur f Clin Pharmacol 1992; 42: 619-22.

30 Bondesen S, Brønnum Schou J, Pedersen V, Rafiolsadat Z, Honoré Hansen S, Hvidberg EF. Absorption of 5-aminosalicylic acid from colon and rectum. Br $¥$ Clin Pharmacol 1988; 25: 269-72.

31 Norlander B, Gotthard R, Ström M. Pharmacokinetics of a 5-aminosalicylic acid enteric-coated tablet in patients with Crohn's disease or ulcerative colitis and in healthy volunteers. Aliment Pharmacol Therap 1990; 4: 497-505.

32 Norlander B, Gotthard R, Ström M. Steady-state pharmacokinetics of enteric coated 5-amino-salicylic acid tablets in healthy volunteers and in patients with Crohn's disease or ulcerative colitis. Aliment Pharmacol Therap 1991; 5: or ulcerative

33 DeLeve LD, Kaplowitz N. Glutathione metabolism and its role in hepatotoxicity. Pharmacol Ther 1991; 52: 287-305.

34 Bostrom B, Erdmann G. Cellular pharmacology of 6-mercaptopurine in acute lymphoblastic leukemia. $\mathrm{Am} f$ Pediatr Hematol Oncol 1993; 15: 80-6.

35 Gruber SA. Locoregional immunosuppression of organ transplants. Immunol Rev 1992; 129: 5-30.

36 Gruber SA, Hrushesky WJM, Cipolle RJ, Erdmann GR, Burke BA, Skjei KL, et al. Local immunosuppression with reduced systemic toxicity in a canine renal allograft model. Transplantation 1989; 48: 936-43. 